\title{
Spatio-temporal response mechanism of physiological characteristics of Abies georgei var. smithii to altitude
}

\author{
Kang Chen ${ }^{1,2,3}$, Jiangrong Li ${ }^{1,2,3, *}$, Weilie Zheng ${ }^{1,2}$, Zhiying Fan ${ }^{1,2,3}$, and Kaiwen Pan $^{4}$ \\ ${ }^{1}$ Institute of Plateau Ecology, Tibet Institute of Agriculture and Animal Husbandry, Tibet, Linzhi 860000, China \\ ${ }^{2}$ Key Laboratory of Tibet Plateau Forest Ecology Ministry of Education, Linzhi 860000, China \\ ${ }^{3}$ National Field Scientific Observation and research station for Alpine forest ecosystems, Linzhi, Tibet, Linzhi 860000, China \\ ${ }^{4}$ CAS Key Laboratory of Mountain Ecological Restoration and Bioresource Utilization \& Ecological Restoration Biodiversity \\ Conservation Key Laboratory of Sichuan Province, Chengdu Institute of Biology, Chinese Academy of Sciences, Chengdu 610041, \\ China
}

\begin{abstract}
Abies georgei var. smithii (Abies George I varsmithorr. II (Viguie et Gaussen) Cheng et 1.) belongs to Abies of Pinaceae, which is distributed in the southeast of Tibet, southwest of Sichuan and northwest of Yunnan. In this study, Abies georgei var. smithii in Sejila Mountain of southeastern Tibet was studied, the contents of Malondialdehyde (MDA), proline (pro), hydrogen peroxide $\left(\mathrm{H}_{2} \mathrm{O}_{2}\right)$, soluble sugar and chlorophyll as well as the activities of superoxide dismutase (SOD) and superoxide dismutase (SOD) in the leaves, twigs, tree stems and roots of Abies georgei var. smithii were measured at different altitudes in the growing and non-growing seasons, single factor analysis of variance and multiple comparison were used to process the data. The results showed that the contents of Malondialdehyde (MDA), proline (pro) and hydrogen peroxide $\left(\mathrm{H}_{2} \mathrm{O}_{2}\right)$ in the roots of Abies georgei var. smithii were significantly higher than those of other tissues in both growing and non-growing seasons, the content of chlorophyll in the leaves increased at first and then decreased with the elevation gradient, on the contrary, the ratio of chlorophyll a/b (CHLA/CHLB) increased with the elevation gradient. The activities of Peroxidase (POD) and superoxide dismutase (SOD) were the lowest. When the altitude was more than $4300 \mathrm{~m}$, the activities of POD and SOD decreased. The results showed that the physiological resistance of Abies georgei var. smithii decreased when the elevation was over $3900 \mathrm{~m}$, which was not beneficial to the growth and development of Abies georgei var. smithii, therefore, the distribution of Abies georgei var. smithii along the higher elevation gradient was limited by the unfavorable environmental factors at high altitude.
\end{abstract}

\section{Introduction}

Linzhi, Tibet, as a small river in the south of Tibet, has high vegetation richness and obvious changes in altitude gradient. With the increase in altitude, environmental factors such as temperature, humidity, sunlight radiation, and atmospheric pressure have all undergone drastic changes, which have become a hot spot in the academia to study plant changes in the environment. In high-altitude areas, the growth and development of vegetation is restricted by multiple factors such as moisture, light, temperature, etc. However, there is little knowledge about how the altitude gradient affects the intrinsic physiological characteristics of vegetation. The alpine area of Sejila Mountain has distinct topography and landforms and complex and diverse climate, especially the vertical climate change is obvious. It is an ideal place to study the adaptation of vegetation to external environmental changes and molecular evolution [1]. Subalpine coniferous forest is a unique vegetation type of Sejila Mountain. It is mainly composed of two dominant species of fir and spruce. It has important functions such as water conservation, regional climate regulation, and biodiversity conservation. Subalpine coniferous forest has strong adaptability to the external environment, and its anti-interference ability is extremely strong, and its growth status changes significantly with environmental conditions. However, there is not much research on the adaptive mechanism of the Sejila coniferous forest to environmental changes.

Abies georgei var. smithii is a variety of fir genus Abies georgei var. smithii in the Pinaceae family. It is one of the main tree species of subalpine dark coniferous forests on the Qinghai-Tibet Plateau. One of the dominant species of line tree species [2]. In this study, the Sejila Mountain Abies georgei var. smithii as the research object, under the factors of altitude gradient, the chlorophyll, soluble sugar, proline, hydrogen peroxide, chlorophyll, soluble sugar, proline, hydrogen peroxide, The content of malondialdehyde and the activity of superoxide dismutase (SOD) and (Peroxidase) POD reveal the response mechanism of the altitude gradient to

* Corresponding author: ljrong06@126.com 
the physiological characteristics of fir.

After studying its internal physiological and biochemical processes in response to different altitudes, comparing its laws and differences with altitude gradients, and exploring the physiological and ecological adaptations of Abies georgei var. smithii to the growing and non-growing seasons, it can provide a global basis for the Tibet region of my country. The sustainable development of forest ecosystems and the restoration and reconstruction of degraded ecosystems under the background of climate change can provide theoretical basis, and can also provide scientific guidance for the protection of natural forests in Tibet.

\section{Materials and methods}

\subsection{Overview of the research site}

The study area is located in the Sejila Mountain National Forest Nature Reserve in Tibet $\left(29^{\circ} 10^{\prime} \sim 30^{\circ} 15^{\prime} \mathrm{N}\right.$, $93^{\circ} 12^{\prime} \sim 95^{\circ} 35^{\prime} \mathrm{E}$ ), which belongs to the Nyainqentanglha Mountain Range, is the eastern and central part of Nyingchi County, Tibet,and the western boundary zone. sejila Mountain is a typical subalpine temperate semi-humid climate zone. It is warm in winter and cool in summer, and the dry and wet seasons are obvious. The altitude is $3800-4300 \mathrm{~m}$, the annual average temperature is $-0.73^{\circ} \mathrm{C}$, the highest monthly average temperature in July is $9.23^{\circ} \mathrm{C}$, and the lowest monthly average in January Temperature $-13.98^{\circ} \mathrm{C}$. The average annual sunshine hours are $1150.6 \mathrm{~h}$, the average annual precipitation is $1134.1 \mathrm{~mm}$, and the average annual evaporation is $544.0 \mathrm{~mm}$. The rainy season is from June to September, and the precipitation accounts for $75 \%-82 \%$ of the whole year[3]. Due to the large changes in the altitude gradient of Sejila Mountain, obvious climate changes have formed, and the types of forest communities have also formed greater differences here, which specifically show more obvious laws of the vertical distribution of mountains. As the altitude rises by $100 \mathrm{~m}$, the average temperature drops by about $0.86^{\circ} \mathrm{C}$. Therefore, the distribution of many tree species is restricted by the extremely high mountain environment. Abies georgei var. smithiiis mainly distributed at an altitude of $3100 \mathrm{~m}-4300 \mathrm{~m}$. With the increase of altitude, the proportion of important values of Abies georgei var. smithii in the community increased gradually. When the altitude exceedsed $3550 \mathrm{~m}$, the dominant populations were gradually replaced by Fir, and the distribution of other tree species was less.

\subsection{Research methods}

\subsubsection{Field sampling}

According to the distribution area of Fiesta japonicus in the Sejila Mountain Forest Nature Reserve, this study set five sampling points on the altitude gradient of $3500 \mathrm{~m}-4300 \mathrm{~m}$ in the reserve, and a total of 3 altitude gradient experimental sample points: A $-3500 \mathrm{~m}$,
B-3900m, C-4300m. At each sampling point on each altitude gradient, five adult trees with basically the same growth and physiological health were selected to sample their leaves, branches, stems, and roots. Divide each tree into four directions: east, west, south, and north. Pick mature and equal leaves from annual branches around the crown, mix them, and number them uniformly.

Then take about $200 \mathrm{~g}$ of the core part of the tree and bring it back to the laboratory for processing. Physiological indicators of the leaves, branches, stems and roots of Fir cuspidate were measured in the laboratory, and the measurement of each physiological indicator was repeated three times.

\subsubsection{Determination of physiological indicators}

Use colorimetric method to determine the total chlorophyll, chlorophyll a, chlorophyll b content [4]; use the TBA colorimetric method to determine the MDA content [5]; determine the proline content using the ninhydrin colorimetric method [6]; starch and solubility The sugar content was determined by the anthrone sulfate method [7]; the hydrogen peroxide content was determined by the Jiancheng biological kit method [8]; the catalase POD and the superoxide dismutase SOD activity were measured by the Jiancheng biological kit method [9].

\subsubsection{Data analysis}

Use SPSS 20 to perform one-way ANOVA on the experimental data, analyze the differences in physiological indicators between different altitudes and different vegetative organs, and use Excel to analyze and plot the experimental data.

\section{Results and analysis}

\subsection{The influence of different altitudes on the MDA content of Abies georgei var. smithii}

It can be seen from Figure 1 that with the increase in altitude, the content of MDA generally increases first and then decreases. The content is highest at the root of $3900 \mathrm{~m}$ above sea level, which is an increase of $6.06 \mathrm{~g} / \mathrm{kg}$ compared with the lowest altitude of $4300 \mathrm{~m}$. The difference reached a significant level $(\mathrm{P}<0.05)$. In addition, the MDA content in roots is the highest compared to other parts in both the growing season and the non-growing season. This indicates that the root membrane lipid peroxidation is strong, and the environment is The root cell membrane caused some damage. It can also be seen from Figure 2 that the changing trend of malondialdehyde content in the non-growing season is roughly the same as that in the growing season. There are significant differences in the content of malondialdehyde in different parts and altitudes in both the growing season and the non-growing season $(\mathrm{P}<0.05)$, The highest content in the root at $3900 \mathrm{~m}$ altitude, compared with the lowest 
pole at $4300 \mathrm{~m}$ altitude, the difference reached a very significant level $(\mathrm{P}<0.01)$. The above two items show that, in terms of parts, regardless of the growing season or the non-growing season, the firs at different altitudes suffer the least stress at the stem and the highest at the root.
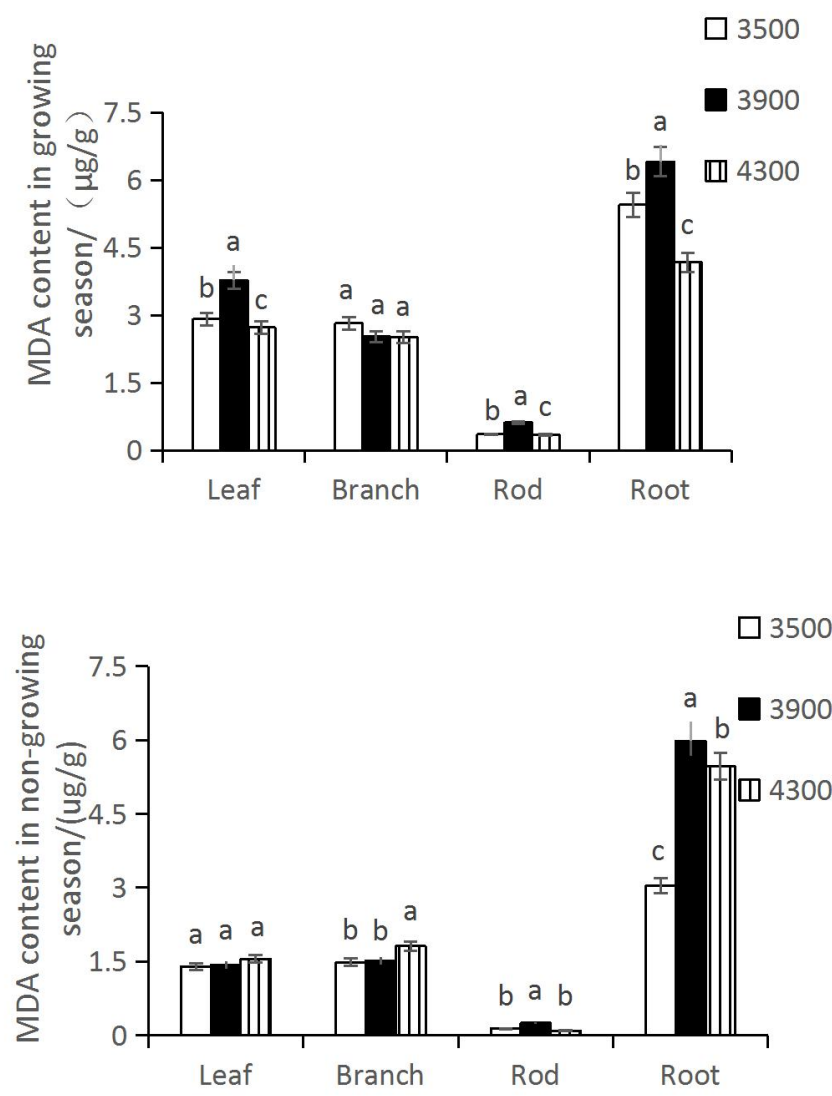

Fig. 1. Content of Malondialdehyde in the tissue of Abies georgei var. smithii in the growing season and non-growing season. The difference between the different letters in the note of the chart indicated that the difference was significant ( $\mathrm{P}$ $<05)$. Same as below

\subsection{Effects of different altitudes on the osmotic adjustment substances of Abies georgei var. smithii cells}

Studies have shown that low temperature increases the content of free proline and soluble sugar, and accumulates them to adjust the osmotic potential of tissues to achieve the purpose of cold resistance, and the accumulation index is related to the stress resistance of plants[10], Abies georgei var. smithii has the highest root content at an altitude of $3900 \mathrm{~m}$ during the growing season, which is $21.74 \%$ higher than the stem at the lowest soluble sugar content under the same altitude gradient. During the growing season, the soluble sugar content of leaves presents an increasing trend with elevation. Between $3500 \mathrm{~m}$ and $4300 \mathrm{~m}$ above sea level, regardless of the growing season or the non-growing season, the soluble sugar content in the stems first decreases and then increases as the altitude increases. But for the same altitude gradient, the content of the

vegetative organs in different parts is significantly lower than that in other parts, and there is a very significant difference $(\mathrm{P}<0.01)$.
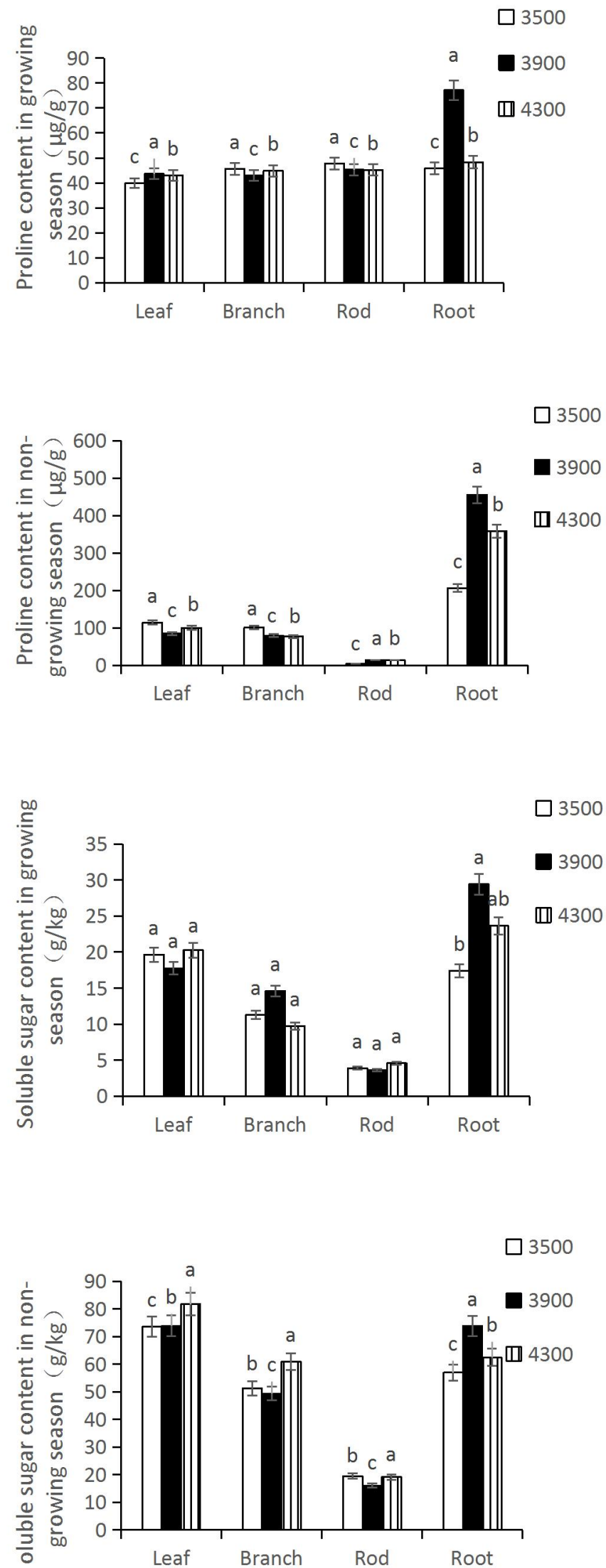
Fig. 2. Effects of different altitude on osmotic adjustment substances in Abies georgei var. smithii cells

In general, during the growing season, the leaves and roots of fir leaves and roots are most stressed by the environment, which may be under low temperature and drought stress. In the non-growing season, the content of each altitude gradient in the root was significantly higher than that in other parts, indicating that the root was under strong environmental stress. The soil is low in the non-growing season, and the concentration of soluble sugar must be increased to lower the freezing point of the cytoplasm. Prevent cells from freezing and make them survive the low-temperature season.

It can be seen from Figure 2 that the content of proline in the roots of Fir in the growing season and the non-growing season is significantly higher than that in other parts, showing a trend of first increasing and then decreasing, especially when the altitude gradient is $3900 \mathrm{~m}$, the content is the highest in the growing season. It is 1.68 and 1.37 times the altitude gradient of $3500 \mathrm{~m}$ in the non-growing season, respectively, forming a significant difference. For other vegetative organs, the content of proline in the non-growing season is higher than that in the growing season, indicating that the non-growing season is more affected by the environmental stress caused by the habitat than the growing season. In the non-growing season, the proline content in the rods showed a trend of first increasing and then decreasing on the altitude gradient, and significant differences were formed in each altitude gradient $(\mathrm{P}<0.05)$.

\subsection{The Influence of Different Altitudes on the Starch Content of Abies georgei var. Smithii}

According to the analysis of Figure 3, the starch content of the fast-tip long fir in the growth season is higher than that in the non-growth season, indicating that during the growth season, it resists the environmental stress of the non-growth season by accumulating more starch. During the growing season, the starch content in the $3500 \mathrm{~m}$ blades at sea level was significantly higher than that in the $3900 \mathrm{~m}$ and $4300 \mathrm{~m}$ blades, and the difference reached significant levels $(\mathrm{P}<0.05)$, besides, the starch content in the root and rod was at the altitude gradient Under the influence, the difference between $3500 \mathrm{~m}$ and $3900 \mathrm{~m}$ and $4300 \mathrm{~m}$ was not significant $(\mathrm{P}>0.05)$, but the difference between $3900 \mathrm{~m}$ and $4300 \mathrm{~m}$ was significant $(\mathrm{P}<0.05)$. Starch accumulated through nutritional organs shows that the sharp-tip long fir is the least stressed at an altitude gradient of $3500 \mathrm{~m}$, and when the altitude exceeds $3500 \mathrm{~m}$, the habitat makes the growth of the fast-tip long fir under environmental stress, which is not conducive to its growth.
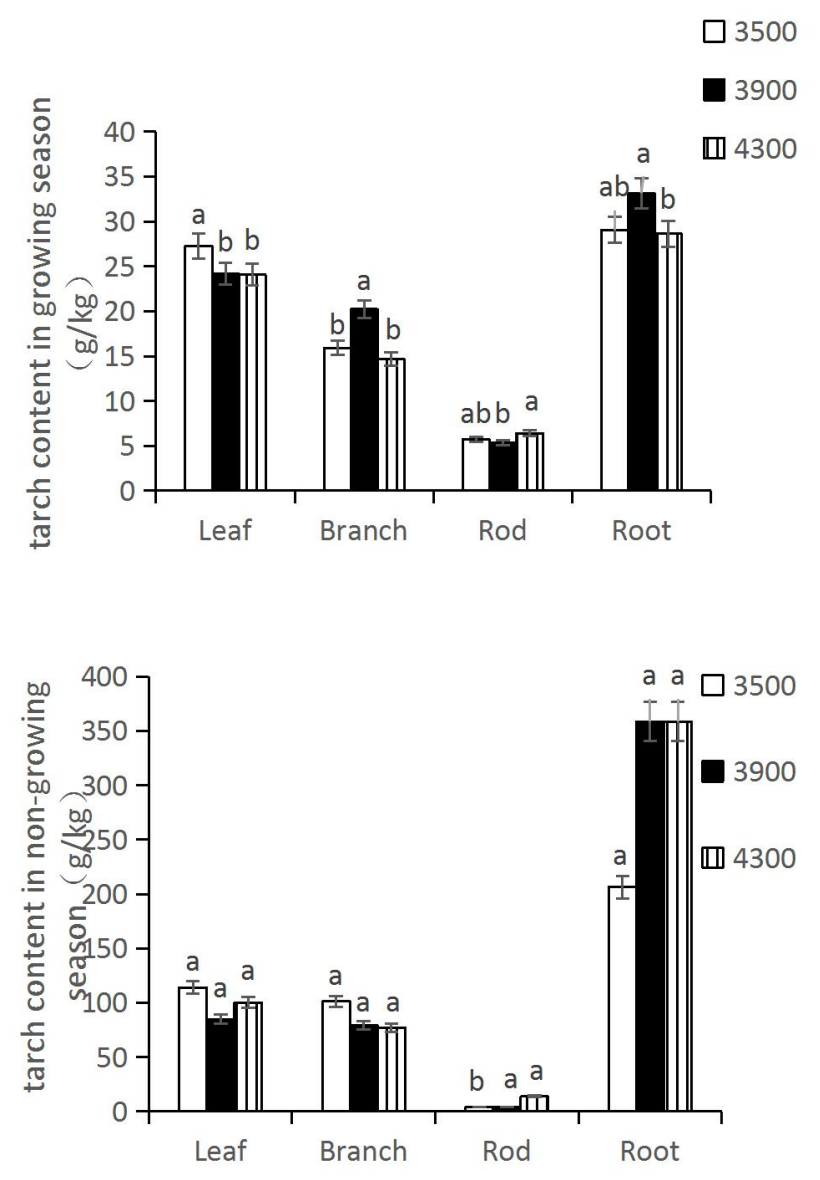

Fig. 3. Starch content in the growing season and non-growing season

\subsection{Effects of different altitudes on the hydrogen peroxide content of Abies georgei var. Smithii}

As can be obtained from Figure 4, during the growth season and the non-growth season, there is a significant difference between the massive hydrogen peroxide content at the root of the $3500 \mathrm{~m}$ rapid tip fir root and the altitude of $3900 \mathrm{~m}$ and $4300 \mathrm{~m}(\mathrm{P}<0.05)$, which indicates that when the altitude gradient is at $3500 \mathrm{~m}$, its roots are less stressed by habitats than at $3,900 \mathrm{~m}$ and $4300 \mathrm{~m}$ above sea level, and are more suitable for physiological activities at its roots. However, for the leaves, the hydrogen peroxide content was significantly higher than $3900 \mathrm{~m}$ and $4300 \mathrm{~m}$ during the growth season at an altitude gradient of $3500 \mathrm{~m}$, and the difference was significant $(\mathrm{P}<0.05)$, possibly at an altitude of $3500 \mathrm{~m}$ during the growing season Where the leaf site is exposed to strong sunlight radiation, it needs more hydrogen peroxide to eliminate active oxygen in the body, to ensure its normal physiological activity, but in the non-growth season, this phenomenon is the opposite of the growth season, non-growth season, due to the low temperature, drought and other form a new physiological stress, this situation has been created. 

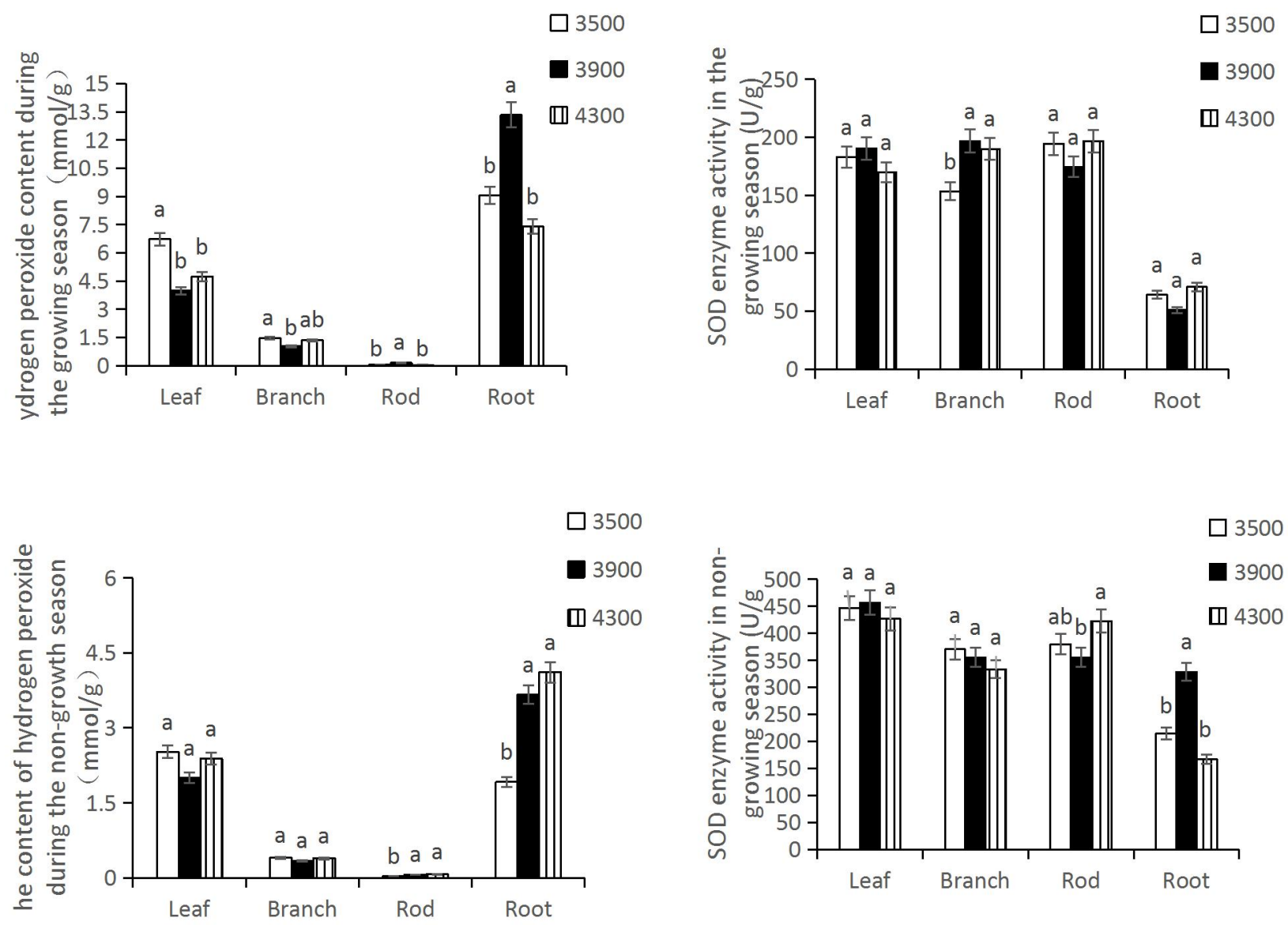

Fig. 4. Content of hydrogen peroxide in growing season and non-growing season

\subsection{Effects of different altitudes on the antioxidant system of acute Abies georgei var. Smithii}

As shown in Figure 5, at $3500 \mathrm{~m}, 3900 \mathrm{~m}$ and $4300 \mathrm{~m}$ gradients, the change of SOD activity in the roots, leaves and poles of the fast-tipping fir during the growing season was not significant, and as the elevation gradient rose to $3900 \mathrm{~m}$, the SOD activity in its branches showed a trend of increasing and then decreasing, and $3500 \mathrm{~m}$ and $3900 \mathrm{~m}$, The significant difference of $4300 \mathrm{~m}(\mathrm{P}<0.05)$ indicates that $\mathrm{H}_{2} \mathrm{O}_{2}$ accumulates more reactive oxygen in the body as the altitude rises, which is consistent with hydrogen peroxide content, indicating that after the elevation exceeds $3500 \mathrm{~m}$ during the growing season, the sharp-tip fir is gradually subjected to environmental stress. During the non-growth season, the change of SOD activity in the leaves and branches was not significant, but the SOD activity in the rod varied significantly between $4300 \mathrm{~m}$ and $3900 \mathrm{~m}(\mathrm{P}<0.05)$, and the SOD activity was lowest at the $3900 \mathrm{~m}$ altitude gradient, indicating that during the non-growth season, it was subjected to relatively little environmental stress to adapt to its growth.
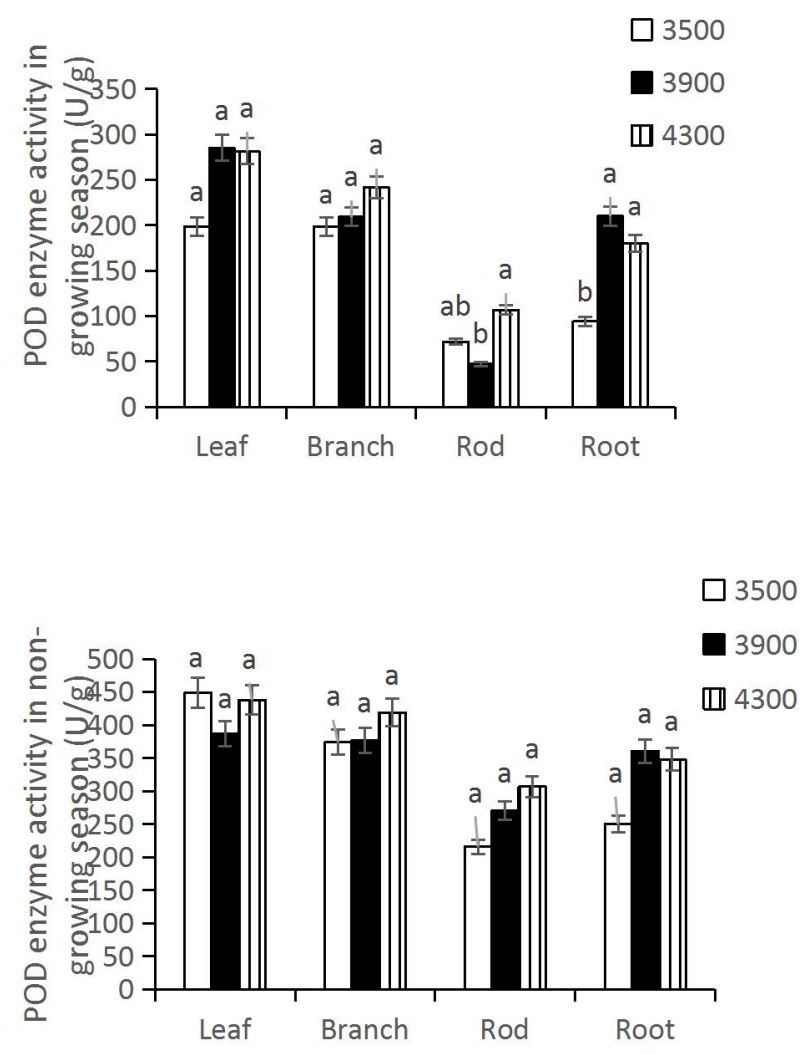

Fig. 5. Effect of different altitude on antioxidant system of Abies georgei var. smithii 
In the growing season its leaf, and branch POD activity in the altitude gradient change is not significant $(\mathrm{P}>0.05)$, but its activity is higher than the rod, root POD activity, which is the opposite of $\mathrm{H}_{2} \mathrm{O}_{2}$ content, 0 The corresponding $\mathrm{H}_{2} \mathrm{O}_{2}$ content with high POD activity is low, and the higher the POD activity, the stronger its resistance to retrograde, therefore, it shows that it is stronger at $3900 \mathrm{~m}$ altitude during the growing season, and it is subjected to strong environmental stress. In the non-growth season, its SOD activity is generally shown to increase with the elevation of its activity, especially the highest activity in the leaves, indicating that the sharp-tip long fir in the high-altitude habitat of its higher activity POD protection of its cell oxidation capacity is strong, strong resistance.

\subsection{Effect of different altitudes on the content of acute long lutein}

Table 1 variation of chlorophyll content with altitude gradient in Abies georgei var. smithii

\begin{tabular}{|c|c|c|c|}
\hline $\begin{array}{l}\text { Altitude } \\
\text { gradient }\end{array}$ & $\begin{array}{c}\text { Chlorophyll a } \\
\text { content } \\
\left(\mathrm{mg} \cdot \mathrm{g}^{-1}\right)\end{array}$ & $\begin{array}{c}\text { Chlorophyll } \\
\text { b content } \\
\left(\mathrm{mg} \cdot \mathrm{g}^{-1}\right)\end{array}$ & Chla/Chlb \\
\hline $3500 \mathrm{~m}$ & $6.37 \pm 0.49 \mathrm{a}$ & $3.43 \pm 0.45 \mathrm{a}$ & $1.77 \pm 0.13 \mathrm{a}$ \\
\hline $3900 \mathrm{~m}$ & $6.87 \pm 0.43 \mathrm{a}$ & $4.15 \pm 0.4 \mathrm{a}$ & $1.72 \pm 0.14 \mathrm{a}$ \\
\hline $4300 \mathrm{~m}$ & $6.11 \pm 0.26 \mathrm{a}$ & $3.54 \pm 0.42 \mathrm{a}$ & $1.92 \pm 0.13 \mathrm{a}$ \\
\hline
\end{tabular}

As can be seen from table 1, there is a significant difference in chlorophyll content in the fast-tipping fir leaves that grow at different altitudes. With the elevation, chlorophyll a (Chla), chlorophyll b (Chlb) and total chlorophyll content showed a trend of first increase and decrease, the content of which reached the highest level at an altitude of $3900 \mathrm{~m}$, compared with $3500 \mathrm{~m}, 4300 \mathrm{~m}$ increased by 1.07 times, 1.12 times. The increase of chlorophyll content is conducive to increasing the absorption of light by the leaves, but at high altitudes, high concentrations of chlorophyll content will lead to radiation damage to plant leaves, so at an altitude of $3900 \mathrm{~m}$, the sharp-tip fir is exposed to strong radiation, which is not conducive to its growth.

\section{Discussion}

\subsection{The of Malondialdehyde adaptive analysis in different altitude tissues}

The amount of propylene dialdehyde content can directly reflect the degree of cell lipid peroxide and plant tolerance to adverse conditions, generally speaking, the higher the level of propylene Malondialdehyde indicates that the plant is subjected to higher degrees of stress and damage. When plants are in adversity, the dynamic balance between the production and elimination of free radicals in cells is broken, resulting in the accumulation of large amounts of reactive oxygen and toxic $\mathrm{OH}^{-}$ Invasive polymeric substances in cells [11]. This accumulation process eventually causes peroxidation of membrane lipids, which can cause damage to the cell membrane system[12]. The more MDA accumulates, the greater the permeability of the cell membrane, the greater the damage it suffers. In this study, the MDA content was highest in the roots of the fast-tip long fir, regardless of the growing season or the non-growth season, followed by the leaf, branch and rod content was the lowest, indicating that the root was subjected to the most severe physiological, especially at an altitude of $3900 \mathrm{~m}$, the content of the root was significantly higher than that of other elevation sites. From the point of view of cell membrane stability of different nutritional organs, this shows that the fast-tip long fir rod is the least stressed in the habitat and has good adaptability. From different altitude point of view, regardless of the growth season or non-growth season, the MDA content of the various nutrient organs at an altitude of $3900 \mathrm{~m}$ is higher than that of other altitude areas, which indicates that the rapid-tip fir at an altitude of about $3900 \mathrm{~m}$ habitat suffered higher damage, its adaptability is weak, not conducive to its growth.

\subsection{Analysis of the adaptability of osmotic regulatory substances in different altitude tissues}

Soluble sugar and proline, as osmotic regulatory substances, have a mitigating effect on dehydration caused by freezing, and also have a protective effect on cell membranes. Soluble sugar mainly comes from the decomposition of carbohydrates such as starch, as well as photosynthesis products such as sucrose[13]. Accumulation in plants during the growing season is important for plant over-growth season high and cold low temperature, in the non-growth season plants through water disintegrating carbohydrates to form soluble sugar, can maintain the stability of the cell membrane and increase the cold resistance of plant cells[14]. In addition, the increase of soluble sugar content in plant cells can improve the concentration of cell fluid, help to maintain the normal metabolism of cells and resist adverse environmental stress. In this study, the soluble sugar content and starch content showed a negative correlation with the increase of altitude gradient. From the point of view of nutrition organs, regardless of the growth season and growth season, leaves, branches, rods, roots of the four nutritional organs, the soluble sugar content and starch content in the root are higher than the other three parts, indicating that the environmental stress in the root is more serious, the acute long fir needs to accumulate more starch and soluble sugar to ensure the stability of the root cell membrane and increase the cold resistance of its cells, which may be caused by high altitude in Tibet, soil and cold thaw. Secondly, the content of its leaves is higher than that of rod, soluble sugar content and starch content in branches, which also plays a role in adapting to drought, low temperature, strong ultraviolet radiation and other adverse environments at high altitudes, which is consistent with Chen Xiaoli's results 
of physiological ecological adaptability of Qinghai spruce and cypress at different altitudes[15].

From the altitude gradient point of view, with the rise of the altitude gradient, the rapid-tip long fir in both the growing season and the non-growth season its soluble sugar content and starch content are shown first increas and then decrease phenomenon, its starch content in the bar gradient $3500 \mathrm{~m}$ and $3900 \mathrm{~m}$, The difference of $4300 \mathrm{~m}$ was not significant $(\mathrm{P}>0.05)$, but the difference between $3900 \mathrm{~m}$ and $4300 \mathrm{~m}$ was significant $(\mathrm{P}<0.05)$, indicating that as the altitude increased, the environment caused some stress on the sharp-tipping fir, starch water dissolved to form soluble sugar to resist the stress of elevation. This may be related to habitats at an altitude of $3500 \mathrm{~m}$ that are more conducive to the growth of the rapid-tip long fir, which is not functioning in the plant's osmotic regulation system. Thus, it is shown that the sharp-tip long fir is the least stressed at $3500 \mathrm{~m}$ altitude gradient, and when the altitude exceeds $3500 \mathrm{~m}$, the habitat makes the growth of the sharp-tip long fir under environmental stress, which is not conducive to its growth. This is consistent with Huang Xiaoxia's conclusion that the physiological characteristics of the fir at different altitudes change at the rapid tip of Yulong Snow Mountain in northwest China[16].

Proline is the product of plant stress environment, many studies by determining the content of proline to identify plant resistance strength. Low temperature is the limiting factor of plant growth and development, and it is also the primary environmental stress to endure for the survival of high-altitude plants[17]. In this study, the content of proline in the rapidly growing fir tissue showed a tendency to increase first and then decrease. This suggests that low temperatures can increase the physiological stress of sharp-tip fir, while high-cold environments promote the accumulation of proline in their bodies in large quantities, and as cold-resistant protective substances for high-cold plants to prevent cold or defrost, regeneration or germination to provide nutrition and energy[18]. Some studies have also confirmed this conclusion, such as Qinghai spruce and cypress leaves in the leaf content and altitude gradient is significantly positive correlation[19]. Drought, too, is another important factor limiting plant distribution and growth. The content of proline in the long-tip fir root is also significantly higher than that of other parts, indicating that its root may be subjected to strong drought stress, the continuous accumulation of proline content helps the root cells or tissues to maintain moisture, so that the root site shows higher drought resistance than other parts[20].

In terms of different altitude gradients, these environmental changes can have important effects on plant morphology and physiology as the altitude increases, the average temperature decreases at high altitudes, atmospheric pressure and radiation increases[21]. Therefore, the change of proline content in plants is the result of coping with the change of many environmental factors and the regulation of the plant's physiological mechanism. In this study, with the rise of altitude gradient, the rapid-tip long fir shows the trend of first rise and then decrease, at the altitude gradient of
$3900 \mathrm{~m}$, its root proline content is significantly higher than other altitude gradients, the root cells at $3900 \mathrm{~m}$ above sea level through the purposeful adjustment of the content of proline in the root to achieve a certain degree to improve the adaptability of rapidly growing fir to environmental drought-induced infiltration stress. It can be seen that, at a certain altitude, the protection system inside the sharp-tip long fir can make it gather high levels of proline after being coerced by the environment, so that the rapidly growing fir is less damaged.

\subsection{Adaptability analysis of hydrogen peroxide in tissues at different altitudes}

$\mathrm{H}_{2} \mathrm{O}_{2}$ plays an important role in the response of plants to environmental stress, such as responding to adversity to produce disease-resistant defense responses, regulating plant growth and development, and participating in many physiological processes such as guard cell stomatal movement[22]. In addition, under strong light, drought, low temperature and other stress conditions, $\mathrm{H}_{2} \mathrm{O}_{2}$ is an inevitable product of the cell photosynthetic electron transport chain. Studies have shown that a large amount of $\mathrm{H}_{2} \mathrm{O}_{2}$ is produced in stomatal guard cells under strong light conditions[23]. Similarly, $\mathrm{H}_{2} \mathrm{O}_{2}$ also participates in cell wall lignification and cross-links hydroxyproline-rich glycoproteins into a network precipitate [24]. Studies have shown that a small amount of $\mathrm{H}_{2} \mathrm{O}_{2}$ has a wide range of physiological and biochemical effects in plants. It can directly act on proteins, lipids, polysaccharides and nucleic acids, and participate in and affect a variety of biological metabolic systems, such as enhancing plant disease resistance and defense responses and participating in cell walls. Lignification and oxidative cross-linking of cell walls, induction of guard cell stomata closure, etc[25].

In this study, the content of hydrogen peroxide in the roots of fir is higher than that in its branches, leaves, and stems during the growing and non-growing seasons. From the perspective of vegetative organs, it indicates that the roots are exposed to the environment in the habitat. The stress is greater, it needs more hydrogen peroxide to eliminate the active oxygen in the body and ensure its normal physiological activity. Secondly, the content of hydrogen peroxide in leaves is also higher than that in branches and stems. Strong ultraviolet radiation and low temperature in high altitude areas are unfavorable factors for leaves. The $\mathrm{H}_{2} \mathrm{O}_{2}$ produced by leaves can ensure the integrity of the photosynthetic electron transport chain of leaf cells and the protection of stoma cells. Normal physiological activities. The content in the rod is the lowest compared to other parts. This result indicates that the cell wall of most of the cells in the rod has been lignified, which has strong stability to the impact of environmental stress.

Analyzed from different altitude gradients, there is a significant difference in the mass content of hydrogen peroxide in the roots of fir at an altitude of $3500 \mathrm{~m}$ and altitudes of $3900 \mathrm{~m}$ and $4300 \mathrm{~m}$, which indicates that when the altitude gradient is at $3500 \mathrm{~m}$, its roots are affected by the habitat relative to altitudes of $3900 \mathrm{~m}$ and 
$4300 \mathrm{~m}$. The stress is less, and it is more suitable for the physiological activities of its roots.

\subsection{Adaptability analysis of antioxidant system in tissues at different altitudes}

SOD and POD are important antioxidant enzymes in plants, which can remove excess $\mathrm{O}^{2-},-\mathrm{OH}$ and other free radicals in plants. Adversities such as low temperature and strong radiation destroy the balance of free radical metabolism in plants, causing the production of reactive oxygen species (ROS), causing damage to the plant cell membrane system, and even cell death in severe cases[26]. The antioxidant enzyme system in the cell, such as superoxide dismutase (SOD), peroxidase (POD), catalase (CAT), etc. can effectively remove excess free radicals and protect cells from reactive oxygen free radicals. Damage. Therefore, the activity of the antioxidant enzyme system in plants is an important performance of whether plants can adapt to a bad environment, and it is closely related to the ability of plants to resist stress[27]. As the altitude changes, various ecological factors in the environment have changed. In the process of long-term adaptation and evolution of alpine plants, a set of physiological adaptation mechanisms restricted by genetics have been formed in the body to resist harm caused by unfavorable environments. Adversities such as low temperature and strong radiation destroy the balance of free radical metabolism in plants, causing the production of reactive oxygen species (ROS), causing damage to the plant cell membrane system, and in severe cases, cell death, while the antioxidant enzyme system in the cell, such as superoxide dismutation Enzymes (SOD), peroxidase (POD), catalase (CAT), etc. can effectively scavenge excess free radicals and protect cells from the damage of reactive oxygen free radicals. Therefore, the activity of the antioxidant enzyme system in plants is an important performance of whether a plant can adapt to a bad environment, and it is closely related to the ability of plants to resist stress[28]. In this study, the SOD activity and POD activity in the leaves of Abies georgei var. smithii both in the growing season and the non-growing season are higher than those in other parts, indicating that the leaves can survive under freezing conditions and are related to their complete antioxidant protection system. And the low temperature and strong radiation of the external environment may increase the antioxidant enzyme activity of plants and stimulate the cell's own defense system, showing high antioxidant enzyme activity. However, the antioxidant enzyme activity in the roots is low, and it can be considered that the roots have strong adaptability in several vegetative organs of fir.

From the analysis of different altitude gradients, under the gradients of $3500 \mathrm{~m}, 3900 \mathrm{~m}$, and $4300 \mathrm{~m}$, the SOD activity in the roots, leaves, and stems of Abies georgei var. smithii the growing season does not change significantly, but as the altitude gradient rises to $3900 \mathrm{~m}$, its SOD activity does not change significantly. The SOD activity in the branches first increased and then decreased, and the difference between $3500 \mathrm{~m}$ and
$3900 \mathrm{~m}$ and $4300 \mathrm{~m}$ was significant $(P<0.05)$, indicating that with the increase in altitude, $\mathrm{H}_{2} \mathrm{O}_{2}$ and active oxygen in the body accumulate more, which is comparable to the content of hydrogen peroxide. It is consistent, indicating that after the altitude of the growing season exceeds $3500 \mathrm{~m}$, the firs with sharp-pointed long buds are gradually subjected to environmental stress and can be considered as the most ideal distribution area for firs with long-buds on the uncomfortable ones.

\subsection{Adaptability analysis of chlorophyll content in leaves at different altitudes}

Chlorophyll is an important component of plant photosynthetic complex, which is mainly involved in the absorption, transmission and transformation of light energy in photosynthesis. The chlorophyll content directly reflects the strength of plant photosynthesis. Photosynthetic pigments in leaves participate in the absorption, transmission and transformation of light energy in the process of photosynthesis. The content of photosynthetic pigments directly affects the photosynthetic capacity of trees, of which chlorophyll a (Chla) is the most important[29]. The formation of plant chlorophyll is affected by many environmental factors. Among them, the level of chlorophyll varies with the degree and period of water stress. In the early stage of water factor stress, the level of chlorophyll b (Chlb) shows an upward trend [30]. Under moderate and severe water stress, the Chla/Chlb ratio increases and the total chlorophyll content decreases is one of the factors that inhibit photosynthesis under water stress.

As the altitude increases, the radiation increases and the moisture content decreases, and it increases with the increase in altitude. Determination of photosynthetic pigments in the leaves of Abies georgei var. smithii with different altitude gradients showed that the content of chlorophyll $\mathrm{a}$ and chlorophyll $\mathrm{b}$ increased first and then decreased with the increase of altitude, while the ratio of $\mathrm{Chla} / \mathrm{Chlb}$ showed an increasing trend with the increase of altitude. This shows that at $4300 \mathrm{~m}$, the total solar radiation and ultraviolet radiation are enhanced, and the leaves need to maintain a low chlorophyll content to prevent plant leaves from being damaged by strong radiation, which is conducive to normal photosynthesis. Similarly, the Chla/Chlb ratio reached its maximum value at $4300 \mathrm{~m}$, which indicated that under this altitude gradient, Abies georgei var. smithii was under water stress and the leaves were seriously lacking water. Therefore, this habitat condition was not conducive to the growth of Abies georgei var. smithii.

\section{Conclusion}

This study comprehensively shows that with the increase in altitude, the environment continues to deteriorate (decrease in temperature, increase in solar radiation and ultraviolet rays, drought, and decrease in oxygen and carbon dioxide concentrations, etc.), which gradually increases the environmental stress of fir. From the perspective of the stress on the vegetative organs, among 
the four vegetative organs of fir, the roots are more severely exposed to environmental stress than the leaves, branches, and stems. This may be due to the thinner soil in the Qingzang-Tibet Plateau and the higher organic matter content. Less, the soil temperature is low, caused by repeated freezing of the soil. In terms of antioxidant system, at an altitude of about $3500 \mathrm{~m}$, the MDA content and $\mathrm{H}_{2} \mathrm{O}_{2}$ content are both at the lowest level, and the activities of SOD and POD enzymes are also the lowest. $4300 \mathrm{~m}$ is more suitable for the growth of firs with long buds. When the altitude exceeds $3900 \mathrm{~m}$, the MDA content and $\mathrm{H}_{2} \mathrm{O}_{2}$ increase and reach the maximum value. The activities of various enzymes have decreased to a certain extent. The fir was under severe physiological stress. It can be seen that within a certain altitude range, the internal protective system of Chinese fir can maintain the removal efficiency of active oxygen at a high level, and keep the active oxygen in the cell at a low level, so that the deciduous cedar can keep the active oxygen at a low level, and suffer minor damage.

Combining the physiological indicators in the growing season and the non-growing season, Abies georgei var. smithii less exposed to environmental stress at $3500 \mathrm{~m}-3900 \mathrm{~m}$. When the altitude is higher than $3900 \mathrm{~m}$, with the elevation of the altitude gradient, environmental stress will be caused. Gradually aggravated, it is not conducive to its growth, thereby restricting its distribution to higher altitudes, which may lead to the formation of forest lines.

\section{Acknowledgments}

The successful completion of this paper is inseparable from the guidance of my supervisor, the help and support of my classmates and these enthusiastic people. To that end, I thank them for their help.

In addition, I would also like to thank the Key Laboratory of Tibetan Plateau Forest Ecology of the Ministry of Education (XZA-JYBSYS-2020-Y10) for its funding support.

\section{References}

[1] Huang X X, Tang T, Jiang Y L, et al, 2015, Physiological Characteristics of Abies georgei var. smithii at Different Altitudes in Yulong Snow Mountain, Journal of Zhejiang Forestry Science and Technology, (1): 40-44. (In Chinese)

[2] Xin F M, Liu J M, Yang X L, et al, 2017, Variation in leaf and fine root traits with altitude in Abies georgei var. smithii in Mt. Shergyla. Acta Ecologica Sinica, 37(8): 2719-2728. (In Chinese)

[3] Li Y X, SUO L L C, Yang X L, 2018, Response of Leaf Structure and Photosynthetic Characteristics of Abies georgei var. smithii to Altitudes. Journal of Xiamen University(Natural Science), 57(4): 503-509. (In Chinese)

[4] Li P, Zhang Y J, Liu L T, et al, 2014, Effects of Water Stress on Water Utilization and Leaf Photosynthetic Characteristics in Cotton (Gossypium hirsutum L. ) Seedlings. Cotton Science, 26(2): 113-121. (In Chinese)
[5] Hodges D M, Delong J M, Forney C F, et al, 1999, Improving the thiobarbituric acid - reactive substances assay for estimating lipid peroxidation in plant tissues containing anthocyanin and other interfering compounds. Planta, (207): 604-611.

[6] Wang F, Li Y S, Wang H N, et al, 2016, Effect of Calcium on Growth and Physiological Characteristics of Maize Seedling under Lead Stress. Journal of Soil and Water Conservation, 30(3): 202-207. (In Chinese)

[7] Liu J M, Xin F M, Yang X L, et al, 2017, Basic characteristics and physiological index changes of Abies georgei var. smithii seedlings at different altitudes of Shergyla Mountain. Journal of Zhejiang University(Agriculture \& Life Sciences), 43(5): 623-630. (In Chinese)

[8] Li J, Lin P, Dong Y, et al, 2013, Effect of Morphology and Physiology of Wetland Plants on Plateaus at Different Altitudes, Plant Sclence Journal, 31(4): 370-377.

[9] $\mathrm{Hu} \mathrm{Z}$ C, Luo H, Wu, S M, et al, 2020, Research on Adaptability of Different Types of Seedlings of Lonicera macranthoides Hand-Mazz, Hunan Agricultural Sciences, (10): 36-41. (In Chinese)

[10] Chen X L, 2008, Study on eco-physiological adaptability of PICEA CRASSIFOLIA and Sabina PRZEWALSKII at different altitudes. Gansu: Gansu Agricultural University, (In Chinese)

[11] Liu G L, Zhou X, Pan Z Y, et al, 2010, Effects of Low Temperature Stress on Cold-Resistance Physiological Characteristics of Melaleuca bracteata cv. 'Revolution Gold. Journal of Anhui Agricultural Sciences, 38(22): 12062-12064. (In Chinese)

[12] Hui Y Z, 2013, Analysis of cold resistance of two kinds of Forsythia. Hebei: Agricultural University of Hebe. (In Chinese)

[13] Cheng X Y, 2012, Advances in plant stress physiology. Sciences \& Wealth, (5): 21-21, 149. (In Chinese)

[14] Huang X X, Tang T, Jiang Y L, et al, 2015, Physiological Characteristics of Abies georgei var. smithii at Different Altitudes in Yulong Snow Mountain. Journal of Zhejiang Forestry Science and Technology, (1): 40-44. (In Chinese)

[15] Tang T, Jiang Y 1, FENG Cheng C, et al, 2015, An Eco-anatomical Study on Abies georgei var. smithii Leaves at Gradient Elevation in Northwest of Yunnan. Acta Agriculturae Universitatis Jiangxiensis (Natural Sciences Edition), (2): 218-224. (In Chinese)

[16]Huang X X, Tang T, Jiang Y L, et al, 2015, Physiological Characteristics of Abies georgei var. smithii at Different Altitudes in Yulong Snow Mountain. Journal of Zhejiang Forestry Science and Technology, (1): 40-44. (In Chinese)

[17] Pan H L, Li M H, Cai X H, et al, 2009, Responses of growth and ecophsiology of plants to altitude. 
Ecology and Environmental Sciences, 18(2): 722-730. (In Chinese)

[18] Yang X L, 2007, Study on community structure and plant diversity of timberline forest in Sejila Mountain, Tibet. BEIJING: Beijing Forestry University, (In Chinese)

[19] Chen X L, 2008, Study on eco-physiological adaptability of PICEA CRASSIFOLIA and Sabina PRZEWALSKII at different altitudes. Gansu: Gansu Agricultural University. (In Chinese)

[20] Long J, 2010, Study on cold resistance and its regulation of pepper seedlings. Anhui: Anhui Agricultural University. (In Chinese)

[21] Lu W M. 2011, Studies on the Spectra and photosynthetic physiology of Betula at different altitudes in changbai Mountain. BEIJING: Beijing Forestry University. (In Chinese)

[22] Long J, 2010, Study on cold resistance and its regulation of pepper seedlings. Anhui: Anhui Agricultural University. (In Chinese)

[23] Li G J, 2012, Study on the production of superoxide anion and its function in plants. Biotech World, (004): 24-25. (In Chinese)

[24] Qiao W H, Yang Q W, 2009, Nitric oxide synthesis in plant and responses to abiotic stress. Journal of China Agricultural University, 14(3): 1-6. (In Chinese)

[25] Ma Y L, She X P, Yang S S, 2012, Sphingosine-1-phosphate (S1P) mediates darknessinduced stomatal closure through raising cytosol $\mathrm{pH}$ and Hydrogen peroxide $\left(\mathrm{H}_{2} \mathrm{O}_{2}\right)$ levels in guard cells in Cicia faba. Science in China(Series $C$ ), 42(9): 746-756. (In Chinese)

[26] He J H, Wang W J, Wang P T, et al, 2008, Involvement of Hydrogen Peroxide in Stomatal Closure of Vicia faba L. Induced by Salicylic Acid. Journal of Henan Agricultural Sciences, (3): 23-27. (In Chinese)

[27]Chen X L, Zhang P, Zhang T, et al, 2009, Study on antioxidase activities of Picea crassifolia and Sabina przewalskii at different altitude gradients. Journal of Gansu Agricultural University, 44(1): 118-122. (In Chinese)

[28]Zhang L, 2009, Effects of Se4+on physiological and chemical characteristic of maize root under the stress of $\mathrm{Cd}^{2+}$. Sichuan: Sichuan Normal University. (In Chinese)

[29] Jiang W, 2006, Effects of waterlogging on photosynthetic characteristics and chlorophyll fluorescence parameters of Sweet Cherry. Shandong: Shandong Agricultural University. (In Chinese)

[30]Zhang G F, Zhang Q M, 2003, Effect of water stress on photosynthesis of fruit trees. Chinese Society for horticulture. Anthology of horticulture. 154-157. (In Chinese) 